\title{
Absortância solar e desempenho térmico de tintas frias para uso no envelope construtivo
}

\author{
DORNELLES, Kelen Almeida ${ }^{1}$ \\ CARAM, Rosana Maria \\ SICHIERI, Eduvaldo Paulo \\ ${ }^{1}$ Instituto de Arquitetura e Urbanismo IAU/USP, São Carlos, Brasil. kelen.usp@gmail.com
}

Resumo

Materiais que apresentam baixas absortâncias e altas emissividades são conhecidos como materiais refletivos ou frios. Esses materiais, quando usados como revestimento no envelope construtivo permitem a redução de temperaturas superficiais nos edifícios, minimizando a necessidade de energia para refrigeração em edificações artificialmente condicionadas e tornando mais confortáveis edificações não condicionadas. Neste trabalho, tintas frias e convencionais para pintura externa de paredes e coberturas são avaliadas comparativamente através da caracterização de suas absortâncias e emissividades, assim como o desempenho térmico das mesmas a partir de medições de temperaturas superficiais. Foram selecionadas tintas frias para pintura de paredes e coberturas a partir de produtos disponíveis no mercado nacional e internacional, assim como tintas convencionais de cores correspondentes, totalizando 15 amostras. Os resultados indicaram que tintas frias com baixa absorção no infravermelho-próximo, porém de cor e tonalidade iguais às tintas convencionais, resultam em tintas com menores absortâncias solares. As temperaturas superficiais das amostras expostas ao sol evidenciaram que a absortância solar das tintas afeta diretamente o desempenho térmico das superfícies pintadas, comprovando que quanto mais baixa é a absortância solar da superfície, menor a temperatura do envelope construtivo. Observou-se que o grande potencial de uso das tintas frias em edificações é resultado da diminuição da absortância solar na região do infravermelho, com a possibilidade de se utilizar cores de tonalidade mais escura, porém com melhor desempenho térmico quando comparadas com tintas convencionais de cor e tonalidade semelhantes

Palavras-Chave: absortância solar, tinta fria, desempenho térmico, temperatura superficial.

\begin{abstract}
Materials with low absorptance and high emittance are known as cool materials. When used on the building envelope these materials decrease building surface temperatures, reducing energy demand in conditioned buildings and making more comfortable non conditioned buildings. In this work, cool and standard paints for exterior walls and roofs were comparatively evaluated through their absorptance and emittance properties, as well as the thermal performance evaluation with surface temperature measurements. Cool paints were selected from available products in the Brazilian and international market, as well as standard paints with the same color, totaling 15 samples. Results indicated that cool paints with low near-infrared absorption, but with the same color of standard ones have lower solar absorptance. Surface temperature measurements for samples exposed to the sun confirmed that coatings solar absorptance directly affects the thermal performance of painted surfaces, which corroborates that as lower is the surface solar absorptance, lower is the building envelope temperature. It was observed that the potential to use cool paints on buildings results from the decrease in the near-infrared solar absorptance, with the possibility to use paints with darker colors, but with better thermal performance when compared with standard paints with the same color.
\end{abstract}

Keywords: solar absorptance, cool paint, thermal performance, surface temperature. 


\section{Introdução}

Uma das maiores fontes de ganhos térmicos dos edifícios, principalmente em regiões de clima quente, é a incidência da radiação solar sobre a edificação e, por este motivo, o controle da incidência direta da radiação solar que atinge a envoltória da edificação é um meio eficaz para reduzir os ganhos de calor. Este controle no ganho de calor pode ser obtido através dos efeitos conjugados entre absortâncias e emissividades dos materiais utilizados no envelope construtivo. A emissividade é uma propriedade característica das superfícies definida como o "quociente da taxa de radiação emitida por uma superfície pela taxa de radiação emitida por um corpo negro, à mesma temperatura" (ABNT, 2005). Menores absortâncias reduzem os ganhos de calor solar do edifício, sem necessariamente alterar as perdas. Ao mesmo tempo, aumentar a emissividade pode incrementar as trocas de calor por radiação em ondas longas (GOMES, 1962).

Materiais que apresentam baixas absortâncias e altas emissividades são conhecidos como materiais refletivos ou "frios" (cool materials). Atualmente, existem diversos tipos de materiais classificados como frios disponíveis para uso em edificações ou em superfícies de áreas urbanas, mas sua produção concentra-se principalmente no mercado internacional (EUA e Europa). A maioria desses materiais é de cor branca ou cores claras (Berdahl e Bretz, 1997; Akbari, Pomerantz e Taha, 2001; Doulos, Santamouris e Livada 2004; Synnefa, Santamouris e Livada, 2006). No entanto, é crescente a necessidade de produtos coloridos porque em muitos casos a estética de cores escuras é preferida. Neste sentido, pesquisadores e fabricantes também têm trabalhado no desenvolvimento de materiais frios coloridos para o envelope das edificações para os casos onde cores escuras são preferidas (LEVINSON et al., 2007a, 2007b; SYNNEFA et al., 2007). Esses pigmentos, apesar de não alterarem a cor dos materiais e permitirem desta forma o uso de cores mais escuras, apresentam absortâncias baixas ao infravermelho, minimizando a absorção de calor solar pelas superfícies. Tintas coloridas com pigmentos convencionais tendem a absorver a radiação invisível na faixa do infravermelho, a qual contém mais da metade da energia proveniente do sol. A substituição dos pigmentos convencionais por pigmentos refletivos que absorvem menos radiação infravermelha permite a produção de tintas coloridas similares com menor absortância solar. Essas tintas permitem a redução de temperaturas superficiais nos edifícios, minimizando a necessidade de energia para refrigeração em edificações artificialmente condicionadas e tornando mais confortáveis edificações não condicionadas.

Synnefa, Santamouris e Apostolakis apresentam características espectrais de 10 diferentes tintas frias produzidas na Universidade de Atenas. Os resultados indicaram que todas as tintas contendo pigmentos refletivos ao infravermelho apresentaram refletância solar superior às tintas convencionais de cores correspondentes. Além disso, demonstrou-se que tintas frias coloridas mantêm temperaturas superficiais inferiores às tintas convencionais. Segundo os autores, as tintas frias coloridas podem ser usadas tanto no envelope construtivo (paredes e coberturas) quanto em outras superfícies do ambiente urbano.

No Brasil, ainda é incipiente o desenvolvimento de tintas frias com pigmentos que apresentam baixa absortância à radiação infravermelha. Dos poucos produtos disponíveis comercialmente para diminuir a absorção de calor pelas superfícies, a maior parte é composta de tintas de cor branca, algumas com a presença de cargas especiais como as microesferas cerâmicas. Segundo um fabricante nacional, este tipo de carga quando incorporado à tinta é capaz de refletir, refratar e bloquear o calor, além de dissipá-lo rapidamente, minimizando a transferência de calor através do revestimento. No entanto, resultados de pesquisa realizada por Dornelles et al. (2011) evidenciaram que o grande potencial de uso das tintas brancas com microesferas cerâmicas é devido principalmente à elevada refletância solar que as mesmas apresentam, e não necessariamente pela presença das microesferas.

Uemoto, Sato e John (2010) apresentam resultados de um estudo no qual se investigou o desempenho térmico de tintas frias coloridas não disponíveis comercialmente em relação a tintas convencionais de mesma cor. Os resultados demonstraram que a formulação das tintas produziu alta refletância solar no infravermelho-próximo quando comparadas com as tintas convencionais de mesma cor. Medições de temperaturas superficiais de telhas de fibrocimento pintadas resultaram em diferenças de $10^{\circ} \mathrm{C}$ abaixo para telhas pintadas com tintas frias, em relação às convencionais, quando expostas à radiação IV.

Com base nesses estudos, buscou-se identificar quantitativamente as propriedades térmicas de tintas frias e convencionais e suas influências sobre as temperaturas superficiais de placas metálicas pintadas, obtendo-se um indicativo do potencial de redução das temperaturas superficiais de edificações expostas ao sol e pintadas com tintas frias, quando comparadas com tintas convencionais de cores correspondentes.

\section{Objetivo}

O objetivo desta pesquisa é caracterizar o desempenho térmico de tintas frias desenvolvidas para diminuir a absorção da radiação solar pelas 
superfícies dos edifícios, a partir de medições de absortância solar e emissividade térmica das tintas, e temperaturas superficiais de amostras pintadas expostas ao sol.

\section{Método}

Para a caracterização do desempenho térmico de tintas frias em comparação com tintas convencionais para pintura do envelope construtivo, este trabalho foi dividido em quatro etapas principais:

a. Obtenção da absortância espectral, a partir de medições de refletância com espectrofotômetro.

b. Cálculo da absortância solar, ajustada ao espectro solar padrão.

c. Medições de emissividade com emissômetro portátil.

d. Medições de temperaturas superficiais das amostras expostas ao sol.

\subsection{Amostras de tintas avaliadas}

Para este estudo, foram selecionadas tintas frias para pintura de paredes e coberturas a partir de produtos disponíveis no mercado nacional e internacional, assim como tintas convencionais de cores correspondentes. As tintas escolhidas são do mesmo tipo (acrílica), com diferenciação em relação às cores (claras e escuras) e às suas características de reflexão e absorção da radiação solar (frias ou convencionais). As amostras foram numeradas de T1 a T15, seguidas da legenda CONV: tinta convencional, e REF: tinta refletiva - fria. A nomenclatura das cores foi adotada segundo os catálogos dos fabricantes, conforme características resumidas na tabela 1. Para a confecção das amostras, placas de alumínio com $1,5 \mathrm{~mm}$ de espessura e formato quadrado $(5 \times 5 \mathrm{~cm})$ foram pintadas com as diferentes tintas. Aplicou-se uma demão de um "primer" à base d'água para melhor aderência das tintas à superfície metálica, seguida de três demãos da tinta propriamente dita, com intervalo de duas horas entre demãos. As tintas importadas foram gentilmente cedidas por um fabricante da Grécia.

\subsection{Absortância solar das tintas}

\subsubsection{Medições de refletância em espectrofo- tômetro}

Para a obtenção da absortância solar das tintas, inicialmente foram realizadas medições em laboratório da refletância espectral com espectrofotômetro, segundo padrões definidos pelas normas ASTM E903-12 (ASTM, 2012) e ASHRAE 74-1988 (ASHRAE, 1988). As curvas de refletância espectral foram obtidas com um espectrofotômetro Varian modelo CARY 5G. Para calibrar o equipamento, foram utilizadas duas amostras de referência com refletâncias de $99 \%$ e $2 \%$ (branco e preto de referência, respectivamente). As refletâncias absolutas das amostras ensaiadas foram obtidas para cada comprimento de onda a partir das curvas de base definidas por essas referências, em um gráfico que relaciona comprimento de onda (abscissas) com percentagem de reflexão (ordenadas). Neste trabalho, as amostras foram ensaiadas a cada $1 \mathrm{~nm}$, no intervalo de 300 a $2500 \mathrm{~nm}$, o qual foi subdividido em três, caracterizando as regiões do ultravioleta - UV (300 a $380 \mathrm{~nm}$ ), visível - VIS (380 a $780 \mathrm{~nm}$ ) e infravermelho - IV (780 a $2500 \mathrm{~nm}$ ). Esta faixa de medição foi escolhida por ser a região do espectro que compreende a maior concentração de energia proveniente do Sol, de acordo com o espectro solar padrão definido pela ASTM (2003).

Tabela 1: Características das tintas avaliadas.

\begin{tabular}{|c|c|c|c|c|c|}
\hline Amostra & Tipo & Fabricante/Origem & Cor & Nome & Tonalidade aproximada \\
\hline T1-CONV & Convencional & Nacional & & Branco Neve & Branco \\
\hline T2-REF & Refletiva & Importada & & White Kynar & Branco \\
\hline T3-REF & Refletiva & Importada & & CB002 & Amarelo claro \\
\hline T4-REF & Refletiva & Nacional & & Vermelho óxido & Vermelho escuro \\
\hline T5-REF & Refletiva & Importada & & CB007 & Vermelho escuro \\
\hline T6-REF & Refletiva & Importada & & $\mathrm{CB} 010$ & Marrom escuro \\
\hline T7-CONV & Convencional & Nacional & & Verde Quadra & Verde escuro \\
\hline T8-REF & Refletiva & Importada & & CB018 & Verde escuro \\
\hline T9-CONV & Convencional & Nacional & & Azul França & Azul escuro \\
\hline T10-REF & Refletiva & Importada & & CB004 & Azul escuro \\
\hline T11-REF & Refletiva & Importada & & CB Medium Blue & Azul claro \\
\hline T12-CONV & Convencional & Nacional & & Concreto & Cinza escuro \\
\hline T13-REF & Refletiva & Importada & & CB RAL 7015 & Cinza escuro \\
\hline T14-CONV & Convencional & Nacional & & Preto & Preto \\
\hline T15-REF & Refletiva & Importada & & CB024 & Preto \\
\hline
\end{tabular}




\subsubsection{Absortância solar e ajuste ao espectro solar padrão}

As refletâncias absolutas das amostras ensaiadas são obtidas para cada comprimento de onda a partir das curvas de base definidas por essas referências, em um gráfico que relaciona comprimento de onda (abscissas) com percentagem de reflexão (ordenadas). Para se obter a curva de absortância espectral para as tintas, calcula-se a diferença entre $100 \%$ e a refletância em cada comprimento de onda ( $a=100 \%$ - $\rho)$, pois são superfícies opacas, havendo apenas reflexão e absorção da radiação. As absortâncias médias foram calculadas para os três intervalos do espectro solar, caracterizando as regiões do UV, VIS, IV e TOTAL.

Nas medições com o espectrofotômetro, as lâmpadas simulam a radiação emitida pelo sol, porém de intensidade constante ao longo de todo o espectro. Desta forma, não caracterizam o comportamento ótico das diferentes tintas quando expostas à energia variável proveniente do sol em cada comprimento de onda, pois o espectrofotômetro não faz essa distinção. Assim, resulta-se em distorções da caracterização das superfícies frente à radiação solar, pois esta apresenta variações acentuadas de valores de energia incidente no intervalo estudado, conforme apresentado na norma ASTM G173-03. Para se chegar à quantidade de energia relativa que é absorvida pelas superfícies, os valores de absortância obtidos para cada amostra devem ser corrigidos de acordo com a intensidade da irradiância solar espectral (em W/m²) para cada comprimento de onda, a partir de um espectro solar padrão. Nesta pesquisa, foi adotado o espectro padrão definido pela ASTM G173-03 (ASTM, 2003), o qual considera a radiação hemisférica solar global, composta pela radiação direta, que atinge a Terra vinda diretamente do Sol, e a radiação difusa, que sofre espalhamento pela atmosfera. Para a correção dos valores de absortância obtidos a partir das medições em espectrofotômetro, adotou-se neste trabalho o método de ajuste apresentado por Dornelles (2008), o qual considera dados de irradiância solar global para cada comprimento de onda fornecidos pela ASTM G173-03 e a absortância medida em espectrofotômetro por comprimento de onda. A metodologia detalhada para este cálculo é apresentada na pesquisa de Dornelles (2008).

\subsection{Medições de emissividade}

Para a avaliação da emissividade das amostras, foi utilizado o Emissômetro Portátil da Devices \& Services, modelo AE1, que pertence ao Laboratório de Energia Solar da Escola de Engenharia da Universidade Federal do Rio Grande do Sul - UFRGS. Este equipamento possui um detector de radiação diferencial com áreas de alta e baixa emissividade. $\mathrm{A}$ combinação garante uma resposta constante aproximada para comprimentos de onda térmicos (3.000 a $30.000 \mathrm{~nm}$ ), com precisão de $\pm 0,01 \mathrm{na}$ emissividade. As medições de emissividade foram realizadas de acordo com padrões definidos pela norma ASTM C1371-04 (ASTM, 2004).

De acordo com a ASTM C1371-04, o material a ser medido no emissômetro portátil deve ser um bom condutor térmico como os materiais metálicos, ou deve ser suficientemente fino para que a superfície do material não mude de temperatura devido à energia térmica absorvida do emissômetro durante a medição. Segundo esta mesma norma, a condutância térmica da amostra (isto é, sua condutividade térmica dividida pela espessura da amostra) deve ser maior que 1100 $\mathrm{W} / \mathrm{m}^{2}$.K, correspondendo a uma resistência térmica inferior a 0,00091 $\mathrm{m}^{2} . \mathrm{K} / \mathrm{W}$. Por exemplo, se o material da amostra é vidro, com condutividade térmica cerca de $1,0 \mathrm{~W} / \mathrm{m}^{2} . \mathrm{K}$, então a espessura da amostra deve ser menor que 0,91 mm. Nesta pesquisa, as amostras preparadas em chapas de alumínio de $1,5 \mathrm{~mm}$ de espessura atendem às exigências da norma ASTM C1371-04 para as medições de emissividade.

Para as medições, o detector é aquecido eletricamente a $82^{\circ} \mathrm{C}$, assim a amostra a ser medida não precisa ser aquecida. Após um período inicial de aquecimento de aproximadamente 30 minutos, as emissividades podem ser lidas a cada $1 \mathrm{~min} 30 \mathrm{seg}$. Dois padrões com emissividades conhecidas acompanham 0 equipamento: um de alta emissividade $(\varepsilon \approx 0,90)$ de cor preta e outro de baixa emissividade $(\varepsilon \approx 0,06)$ de aço inoxidável polido. O dissipador de calor que acompanha o emissômetro é responsável por manter as amostras padrão de baixa e alta emissividades e a amostra de emissividade desconhecida à mesma temperatura. Assim, a emissividade de uma superfície desconhecida é medida após o detector ser calibrado com um padrão de emissividade conhecida, que é mantido à mesma temperatura da desconhecida.

\subsection{Medições de temperaturas superfi- ciais}

As temperaturas das superfícies opacas expostas ao sol são bons indicadores de suas absortâncias, pois são diretamente afetadas pela quantidade de energia que é absorvida e refletida por suas superfícies. Assim, para se analisar o efeito das diferenças nas absortâncias das tintas convencionais e frias, foram medidas as temperaturas superficiais das amostras expostas ao sol em um dia de céu limpo na cidade de São Carlos, SP $\left(22^{\circ} \mathrm{S}, 48^{\circ} \mathrm{O}, 860 \mathrm{~m}\right)$.

Para a coleta das temperaturas superficiais foi adotado um sistema eletrônico de aquisição de dados constituído por sensores de temperatura modelo DS18B20 fabricados pela empresa Maxim Integrated Products. Os sensores foram escolhidos por 
apresentarem tamanho bastante reduzido $( \pm 5 \mathrm{~mm})$ e precisão elevada, permitindo a obtenção de resultados mais confiáveis para medição de temperaturas superficiais e facilidade no momento de montagem do sistema. Os sensores de temperatura foram aderidos na face inferior das placas com fita do tipo aluminizada e as amostras foram posicionadas sobre uma placa de isopor, buscando isolá-las termicamente e desta forma evitar trocas por condução e convecção na parte inferior do sistema (Figura 1).

Adicionalmente, mediu-se a temperatura do ar (Temperatura de Bulbo Seco - TBS) ao lado das amostras posicionadas sobre a placa de isopor, para efeito comparativo entre as temperaturas superficiais e a TBS no local de ensaio. O sensor de TBS, do mesmo tipo e modelo utilizado nas medições de temperatura superficial, foi protegido da radiação solar direta e radiação refletida e emitida pelas superfícies ao redor. As amostras foram expostas à radiação solar sobre uma bancada e as medições de temperatura foram realizadas durante 2,5 horas, a intervalo de 1 minuto entre registros. O horário de medição escolhido foi entre $12 \mathrm{~h} 30$ e $15 \mathrm{~h}$ do dia 13 de março de 2012, por ser um horário de grande intensidade de irradiância solar em um dia ensolarado e com altas temperaturas do ar. É importante destacar que as placas de alumínio apresentam elevada condutividade térmica, o que permite a transmissão de calor rapidamente para o sensor de temperatura superficial, sem que se perca grande parte do calor absorvido pelas amostras.

Figura 1: Placa de isopor e amostras expostas ao Sol.

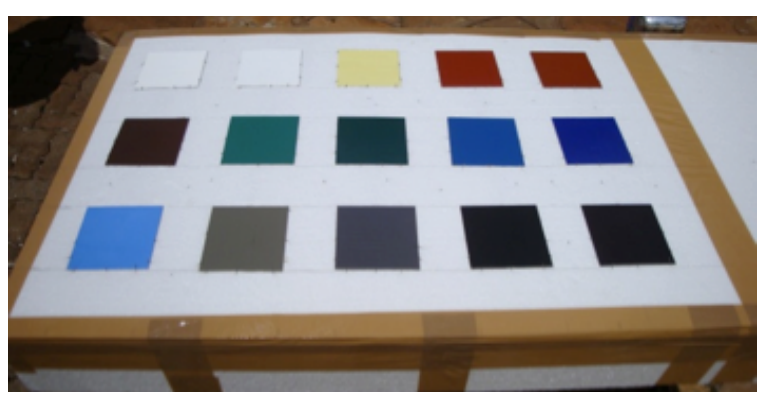

\section{Apresentação e análise de resulta- dos}

\subsection{Absortâncias das tintas}

As curvas de absortância espectral das tintas obtidas a partir das medições em espectrofotômetro são apresentadas nas figuras 2 a 7 , e caracterizam em detalhe seu comportamento espectral. Para a apresentação das curvas, optou-se por separá-las por cor, de tal forma a facilitar as análises comparativas de desempenho das amostras frente à incidência da radiação solar. $A$ absortância média de cada tinta foi calculada para as regiões do UV (300 a $380 \mathrm{~nm})$, VIS (380 a $780 \mathrm{~nm})$, IV (780 a $2500 \mathrm{~nm}$ ) e espectro solar total (300 a $2500 \mathrm{~nm}$ ). As absortâncias foram ajustadas ao espectro solar padrão definido pela ASTM (2003) e são apresentadas na Tabela 2. A absortância solar de cada tinta, utilizada como parâmetro de caracterização da absorção total da radiação solar das superfícies, é apresentada na coluna de absortância TOTAL.

A tinta branca convencional (T1), em comparação com a tinta refletiva (T2) apresentou absortância inferior em todo o espectro (Figura 2), o que implica que a mesma reflete mais a radiação solar, principalmente na região do infravermelho, como se observa na Tabela 2 ( $\mathrm{alV}=9,0 \%$ ). Este comportamento demonstra que mesmo as duas tintas sendo de cor branca, diferenças em sua composição química (que não são avaliadas neste trabalho) podem resultar em comportamentos diferentes quanto à reflexão e absorção da radiação solar. Em relação à tinta de cor amarelo claro (T3), a mesma apresenta baixa absorção na região do visível (36,5\%), com leve aumento no infravermelho, próximo da tinta branca refletiva importada a partir de $1600 \mathrm{~nm}$.

Figura 2: Curvas espectrais de absortância das tintas de cor branco e amarelo claro.

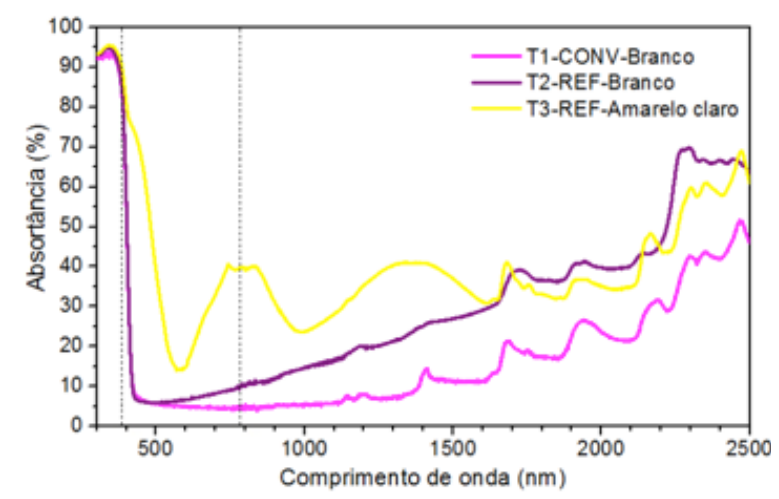

Para as tintas T4 e T5 (vermelho escuro), ambas apresentam baixas absortâncias no IV (Fig. 3). Porém, a tinta refletiva importada (T5), de cor e tonalidade muito similar à tinta refletiva nacional (T4), como se observa em suas curvas de absortâncias espectrais e absortâncias médias no visível (Tabela 2), apresentou menor absortância no IV, ou seja, possui maior potencial refletivo das radiações nesta faixa do espectro. Suas absortâncias nessa faixa enfatizam essas diferenças. No caso da tinta marrom escuro (T6), a mesma apresenta maior absortância em toda a faixa do visível, quando comparadas com as tintas vermelho escuro nacional e importada, comprovando a diferença em sua coloração e tonalidade. Porém, no IV, observa-se uma diminuição considerável da absortância, principalmente para comprimentos de onda acima de $1200 \mathrm{~nm}$, quando a curva de absortância espectral se aproxima consideravelmente da curva relativa à tinta de cor vermelho escuro importada (T5). Este comportamento demonstra a presença de componentes que aumentam a reflexão 
Tabela 2: Absortâncias médias das tintas medidas em espectrofotômetro (Espect) e ajustadas ao espectro solar padrão (Ajust).

\begin{tabular}{|c|c|c|c|c|c|c|c|c|c|c|}
\hline \multirow{3}{*}{ Sigla } & \multirow{3}{*}{$\begin{array}{c}\text { Tonalidade } \\
\text { Aproximada }\end{array}$} & \multirow{3}{*}{ Cor } & \multicolumn{8}{|c|}{ Absortância (\%) } \\
\hline & & & \multicolumn{2}{|c|}{$\overline{\mathbf{U V}}$} & \multicolumn{2}{|c|}{$\overline{\text { VIS }}$} & \multicolumn{2}{|c|}{$\mathbf{I V}$} & \multicolumn{2}{|c|}{ TOTAL } \\
\hline & & & Espect & Ajust & Espect & Ajust & Espect & Ajust & Espect & Ajust \\
\hline T1-CONV & Branco & & 92,2 & 91,7 & 10,0 & 7,6 & 18,2 & 9,0 & 19,4 & 10,2 \\
\hline T2-REF & Branco & & 93,2 & 92,8 & 11,8 & 9,4 & 33,8 & 20,3 & 32,0 & 16,2 \\
\hline T3-REF & Amarelo claro & & 94,3 & 94,3 & 39,3 & 36,5 & 38,8 & 34,2 & 40,9 & 36,7 \\
\hline T4-REF & Vermelho escuro & & 96,8 & 97,0 & 85,9 & 86,0 & 68,0 & 68,9 & 72,3 & 78,5 \\
\hline T5-REF & Vermelho escuro & & 98,6 & 98,8 & 87,2 & 87,2 & 52,0 & 56,2 & 60,1 & 73,4 \\
\hline T6-REF & Marrom escuro & & 96,7 & 97,0 & 93,6 & 93,7 & 52,6 & 64,0 & 61,6 & 80,3 \\
\hline T7-CONV & Verde escuro & & 96,3 & 96,2 & 91,2 & 90,9 & 79,8 & 81,6 & 82,4 & 86,8 \\
\hline T8-REF & Verde escuro & & 96,8 & 97,0 & 88,7 & 89,5 & 74,3 & 67,5 & 77,7 & 79,7 \\
\hline T9-CONV & Azul escuro & & 95,8 & 95,7 & 90,0 & 90,0 & 53,9 & 52,6 & 61,9 & 73,2 \\
\hline T10-REF & Azul escuro & & 96,1 & 95,8 & 86,9 & 87,9 & 85,9 & 80,3 & 86,5 & 84,7 \\
\hline T11-REF & Azul claro & & 92,0 & 91,9 & 56,3 & 57,3 & 68,8 & 55,5 & 67,4 & 57,3 \\
\hline T12-CONV & Cinza escuro & & 94,0 & 94,0 & 71,9 & 71,2 & 76,4 & 71,8 & 76,2 & 72,0 \\
\hline T13-REF & Cinza escuro & & 95,3 & 95,7 & 90,6 & 90,6 & 43,5 & 59,9 & 54,0 & 76,8 \\
\hline T14-CONV & Preto & & 97,1 & 97,2 & 97,5 & 97,5 & 98,7 & 98,2 & 98,4 & 97,8 \\
\hline T15-REF & Preto & & 98,1 & 98,4 & 98,2 & 98,3 & 53,7 & 68,8 & 63,4 & 84,9 \\
\hline
\end{tabular}

(e consequentemente diminuem a absorção) das radiações infravermelhas nas duas tintas, responsáveis pelos ganhos de calor das superfícies.

Figura 3: Curvas espectrais de absortância das tintas de cor vermelho escuro e marrom escuro.

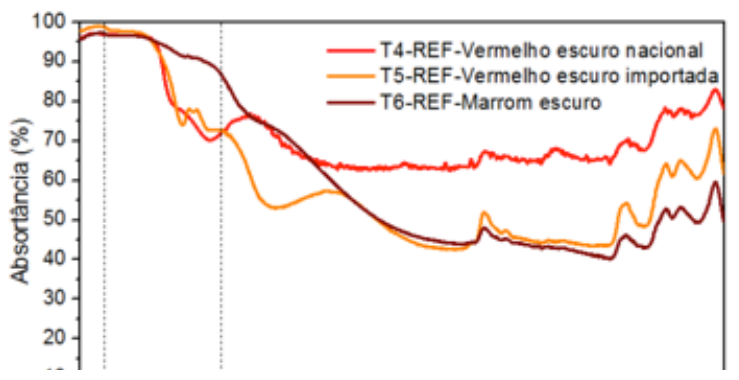

Nas tintas de tonalidade verde escuro (Figura 4), a tinta refletiva (T8) apresentou alta absorção em partes do IV (entre 780 e $1200 \mathrm{~nm}$, e a partir de $2000 \mathrm{~nm}$ ) em relação à tinta convencional (T7), mesmo com absortâncias muito próximas no visível. Este comportamento se evidencia nos valores de absortâncias médias por faixa do espectro (Tab. 2). Para as tintas azul escuro (T9 e T10), as curvas de absortância espectral de ambas indicaram diferenças significativas na região do $\mathrm{IV}$, sendo importante destacar que a menor absortância no IV ocorreu na tinta convencional e não na tinta importada (Figura 5). Esta diferença significativa impactou na absortância solar de ambas, sendo que a tinta convencional apresentou aSolar de $73,2 \%$ enquanto a tinta refletiva teve aSolar de $84,7 \%$. A tinta azul claro refletiva apresentou baixa absorção em comprimentos de onda mais curtos do IV (entre 780 e $1100 \mathrm{~nm}$ ) chegando a $25 \%$ próximo dos $750 \mathrm{~nm}$, porém com aumento considerável entre 1200 e 1800 nm, resultando em uma absortância solar de 57,3\%.
Figura 4: Curvas espectrais de absortância das tintas de cor verde escuro.

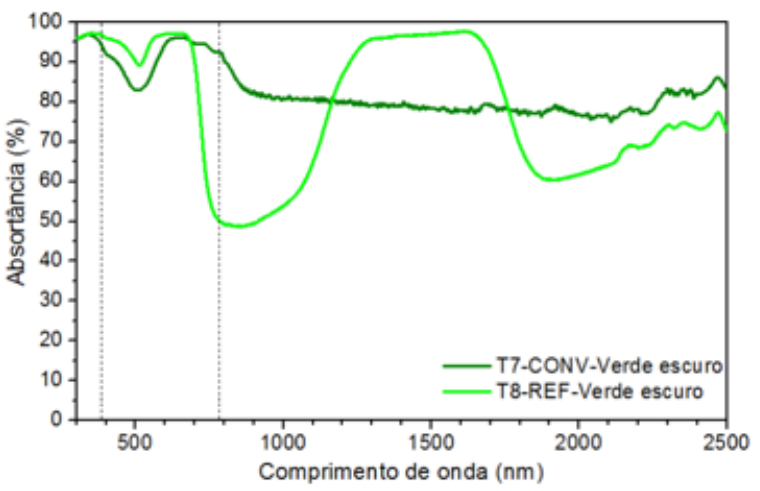

Figura 5: Curvas espectrais de absortância das tintas de cor azul escuro e azul clarol

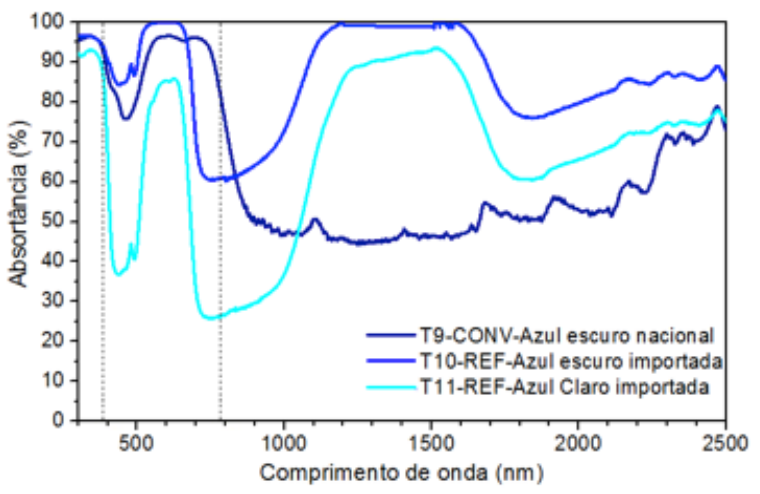

Para as tintas cinza escuro (Figura 6), a tinta refletiva (T13) diminui sua absorção consideravelmente no IV, apesar de apresentar absorção maior que a tinta convencional na região do visível, reforçando seu potencial refletivo das radiações responsáveis pelo ganho de calor solar. A tinta convencional (T12) apresenta alta absorção em toda a faixa do IV. Para as tintas de cor preta há significativa diferença entre 
suas absortâncias na região do infravermelhopróximo (T14: $\mathrm{a}_{\mathrm{IV}}=98,2 \%$ e T15: $\mathrm{a}_{\mathrm{IV}}=68,8 \%$ ) apesar de suas absortâncias na faixa visível serem muito similares (Figura 7 e Tabela 2). Este comportamento ocorre devido à presença dos diferentes componentes químicos adicionados à tinta fria, que lhe conferem alta refletância (e baixa absortância) à radiação na faixa entre 780 e $2500 \mathrm{~nm}$ (IV). Essa diferença pode ser mais bem observada nos resultados das medições de temperatura superficial apresentados a seguir.

Figura 6: Curvas espectrais de absortância das tintas de cor cinza escuro.

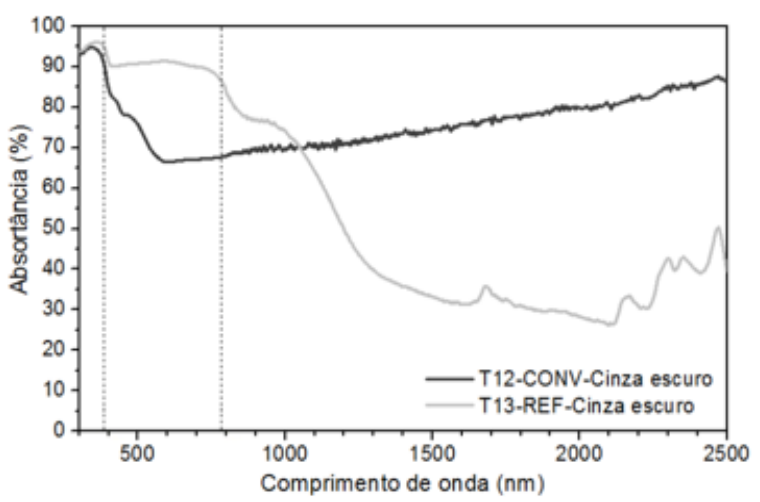

Figura 7: Curvas espectrais de absortância das tintas de cor preta.

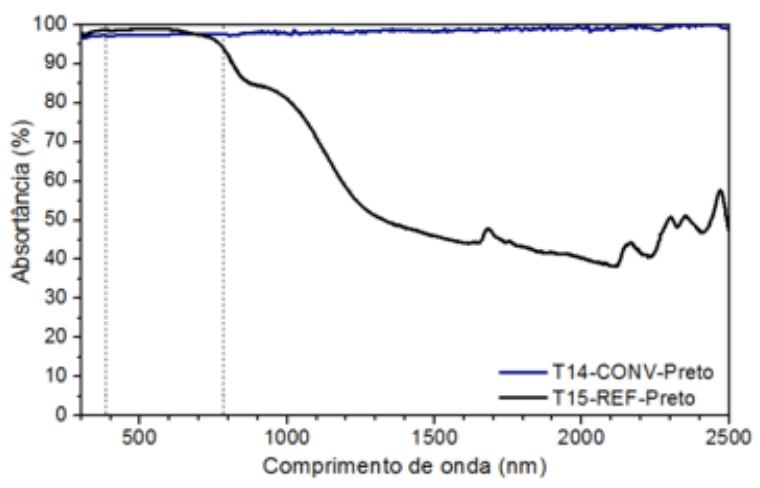

\subsection{Emissividade das tintas}

Foram realizadas duas medições para cada amostra, obtendo-se a média das emissividades das tintas. As tintas do tipo convencional apresentaram emissividades entre 0,90 e 0,91 , enquanto para as tintas refletivas as emissividades variaram entre 0,81 e 0,89 , sendo os valores mais baixos para as tintas refletivas importadas. Os resultados indicaram que as amostras apresentam, de forma geral, alta emissividade, o que as caracteriza como bons emissores de calor. Observou-se, também, que as tintas frias analisadas nesta pesquisa apresentaram emissividades um poucomais baixas queas convencionais, provavelmente devido à presença de certos componentes nas tintas de maior reflexão à radiação infravermelha, e possível menor emissividade térmica. Porém, esta análise não foi feita neste estudo, apenas a medida da emissividade das mesmas. No entanto, é um indicador de desempenho térmico das tintas.

\subsection{Medições de Temperatura Superficial}

$\mathrm{Na}$ figura 8 são apresentadas as variações das temperaturas superficiais das amostras expostas ao sol, assim como a temperatura do ar medida no local. Calculou-se as temperaturas mínimas, máximas e médias para cada uma das amostras nesse período, conforme apresentado na Tabela 3. Pode-se observar que houve uma oscilação de temperatura entre $30^{\circ} \mathrm{C}$ e $90^{\circ} \mathrm{C}$, sendo a maior temperatura superficial registrada para a tinta preta convencional (T14) e a menor temperatura superficial para a tinta branca convencional (T1), ambas com a maior e menor absortância solar, respectivamente. A temperatura do ar (TBS) esteve abaixo da temperatura superficial de todas as amostras.

Analisando-se as cores separadamente, para as tintas de cor branca e amarela pode-se observar que essas amostras, por apresentarem as menores absortâncias, são as que apresentam menores temperaturas superficiais (Figura 9). Para as amostras de cor branca, há pequenas diferenças entre suas temperaturas superficiais, sendo que a tinta branca convencional, de menor absortância solar (10,2\%) apresentou temperaturas cerca de $2^{\circ} \mathrm{C}$ inferior à tinta branca refletiva importada, de absortância solar $16,2 \%$. A amostra de cor amarelo claro, com absortância solar $36,7 \%$, apresentou temperaturas superficiais cerca de $18^{\circ} \mathrm{C}$ acima da temperatura do ar (TBS) no momento da medição.

Para as tintas de cor vermelho escuro e marrom escuro (Figura 10), as curvas de variação da temperatura superficial indicam que as três amostras apresentam valores muito próximos. A tinta marrom escura refletiva importada (T6) apresentou as maiores temperaturas superficiais das três amostras, com média de $72,42^{\circ} \mathrm{C}$, enquanto as demais temperaturas médias das amostras foram de $68,05^{\circ} \mathrm{C}$ para a tinta refletiva vermelho escuro nacional (T4) e $67,68^{\circ} \mathrm{C}$ para a tinta vermelho escuro importada (T5). A tinta marrom escuro apresenta maior absortância solar (80,3\%), sendo também alta sua absortância na região visível do espectro (93,7\%). As tintas refletivas vermelho escuro nacional e importada apresentaram temperaturas médias praticamente iguais, mesmo com diferença de $5 \%$ entre suas absortâncias totais. Isto ocorre porque suas absortâncias na região visível do espectro são muito próximas ( $86 \%$ e $87,2 \%$ ), e como há maior concentração de energia solar nesta região (segundo o espectro solar padrão da ASTM G173-03), há um equilíbrio na quantidade de energia absorvida pelas diferentes tintas quando se faz o ajuste. Isto justifica por que a tinta vermelho escuro importada, mesmo com menor absortância solar e menor absortância no IV, apresenta temperaturas praticamente iguais à tinta refletiva vermelho escuro nacional (Tabela 3). 
Figura 8: Gráfico de temperaturas superficiais das amostras expostas ao sol e temperatura do ar.

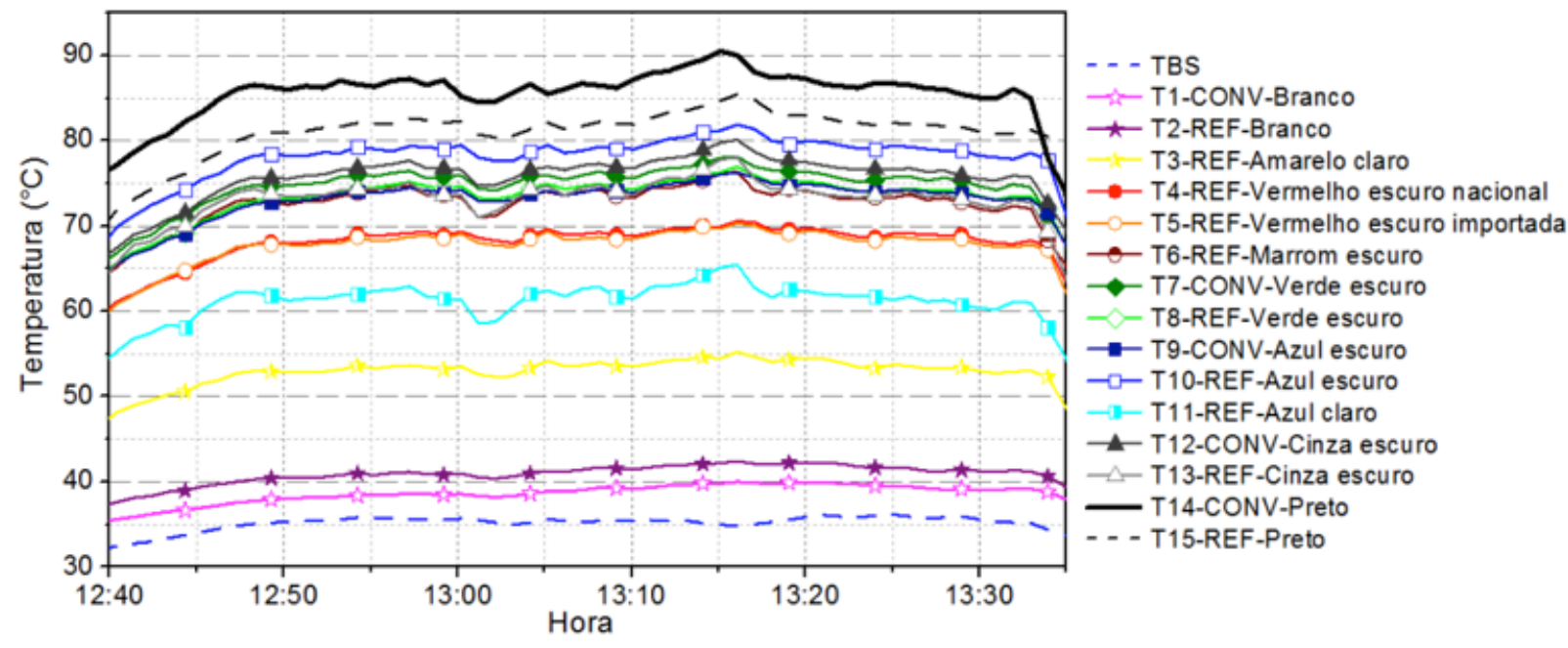

Tabela 3: Temperaturas máximas, mínimas e médias das amostras expostas ao sol e respectivas absortâncias médias.

\begin{tabular}{|c|c|c|c|c|c|c|c|c|}
\hline \multirow{2}{*}{ Sigla } & \multirow{2}{*}{$\begin{array}{c}\text { Tonalidade } \\
\text { aproximada }\end{array}$} & \multirow{2}{*}{ Cor } & \multicolumn{3}{|c|}{ Absortância Ajustada (\%) } & \multicolumn{3}{|c|}{ Temperaturas $\left({ }^{\circ} \mathrm{C}\right)$} \\
\hline & & & VIS & IV & SOLAR & Mínima & Máxima & Média \\
\hline TBS & --- & $\begin{array}{l}-- \\
\end{array}$ & - & $\overline{-}$ & - & 32,44 & 36,18 & 35,14 \\
\hline T1-CONV & Branco & & 7,6 & 9,0 & 10,2 & 35,58 & 40,01 & 38,64 \\
\hline T2-REF & Branco & & 9,4 & 20,3 & 16,2 & 37,63 & 42,42 & 40,90 \\
\hline T3-REF & Amarelo claro & & 36,5 & 34,2 & 36,7 & 46,36 & 55,20 & 52,89 \\
\hline T4-REF & Vermelho escuro & & 86,0 & 68,9 & 78,5 & 61,09 & 70,57 & 68,05 \\
\hline T5-REF & Vermelho escuro & & 87,2 & 56,2 & 73,4 & 59,09 & 70,36 & 67,68 \\
\hline T6-REF & Marrom escuro & & 93,7 & 64,0 & 80,3 & 59,23 & 76,35 & 72,42 \\
\hline T7-CONV & Verde escuro & & 90,9 & 81,6 & 86,8 & 62,00 & 78,12 & 74,58 \\
\hline T8-REF & Verde escuro & & 89,5 & 67,5 & 79,7 & 63,74 & 76,96 & 73,32 \\
\hline T9-CONV & Azul escuro & & 90,0 & 52,6 & 73,2 & 63,73 & 76,28 & 72,98 \\
\hline T10-REF & Azul escuro & & 87,9 & 80,3 & 84,7 & 67,79 & 81,84 & 78,04 \\
\hline T11-REF & Azul claro & & 57,3 & 55,5 & 57,3 & 49,10 & 65,47 & 61,03 \\
\hline T12-CONV & Cinza escuro & & 71,2 & 71,8 & 72,0 & 63,89 & 80,09 & 75,61 \\
\hline T13-REF & Cinza escuro & & 90,6 & 59,9 & 76,8 & 57,42 & 78,02 & 72,93 \\
\hline T14-CONV & Preto & & 97,5 & 98,2 & 97,8 & 65,98 & 90,49 & 85,22 \\
\hline T15-REF & Preto & & 98,3 & 68,8 & 84,9 & 70,78 & 85,42 & 80,87 \\
\hline
\end{tabular}

Figura 9: Temperaturas superficiais das tintas de cor branco e amarelo claro.

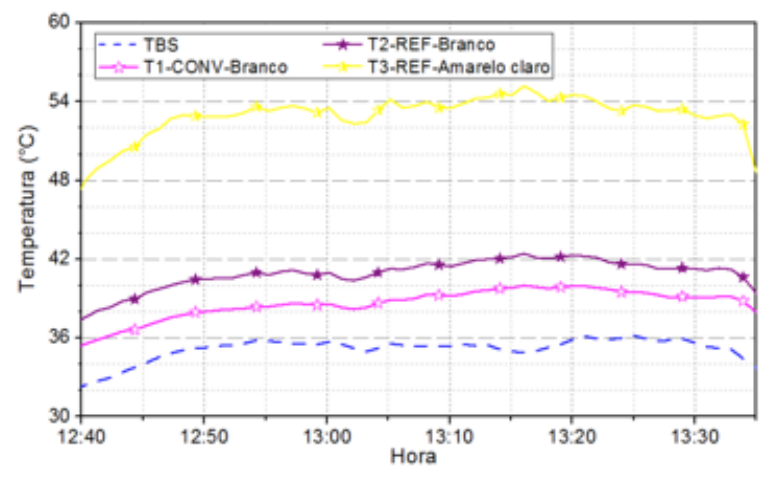

Figura 10: Temperaturas superficiais das tintas de cor vermelho e marrom escuro.

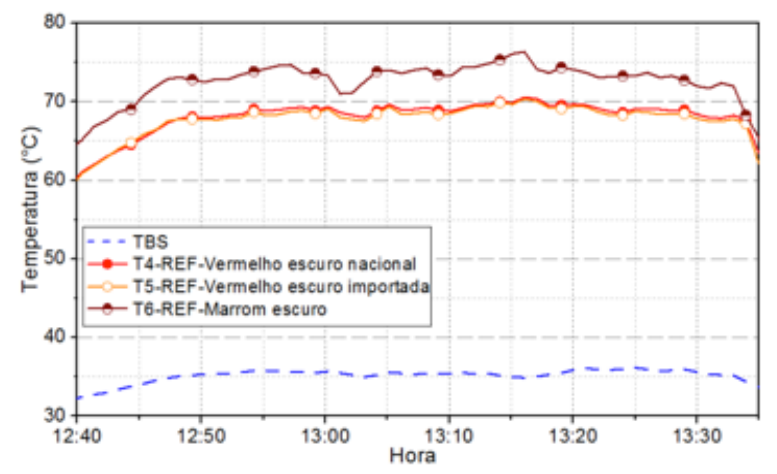


Figura 11: Temperaturas superficiais das tintas de cor verde escuro.

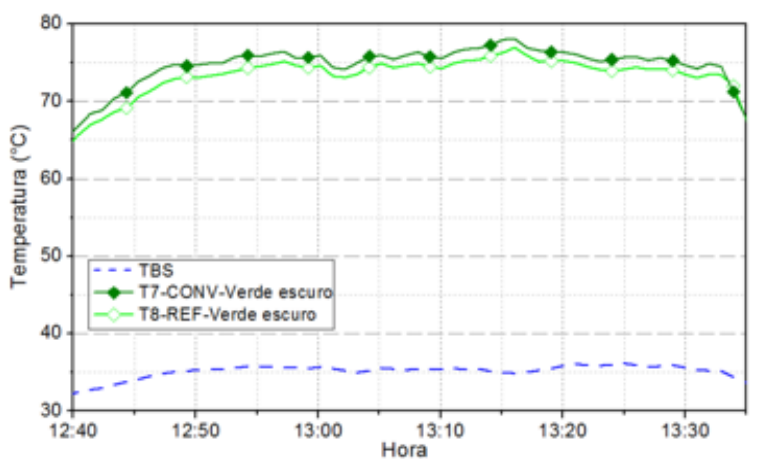

Figura 12: Temperaturas superficiais das tintas de cor azul escuro e azul claro.

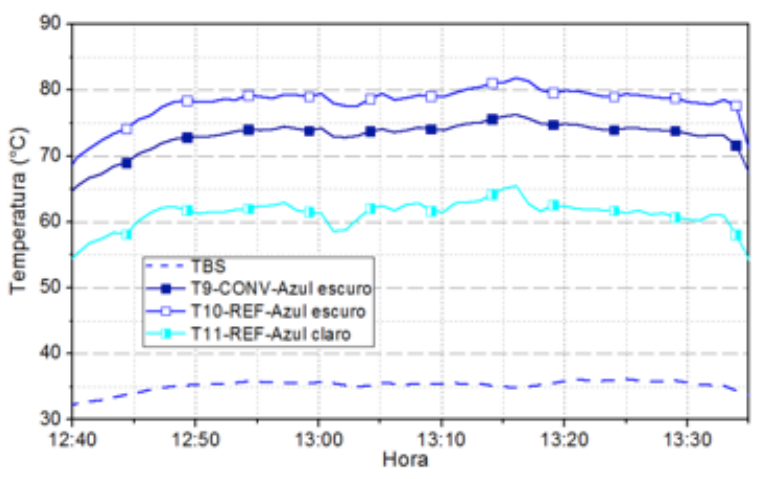

As tintas de cor verde escuro convencional (T7) e refletiva (T8) apresentaram temperaturas superficiais com diferenças de apenas $1^{\circ} \mathrm{C}$ aproximadamente. A tinta refletiva, por apresentar absortâncias abaixo da tinta convencional, apresentou temperaturas superficiais levemente mais baixas (Figura 11). No caso das tintas de cor azul (Figura 12), observa-se que a amostra azul claro (T11) apresentou menor temperatura superficial média (tmédia $=61,03^{\circ} \mathrm{C}$ ), enquanto as demais apresentaram temperaturas de $72,98^{\circ} \mathrm{C}$ para a tinta convencional (T9) e $78,04^{\circ} \mathrm{C}$ para a tinta refletiva (T10). Este comportamento é explicado pelas diferenças entre as respectivas absortâncias totais das amostras, sendo que a tinta azul de maior absortância solar (T10, refletiva) foi a que apresentou maiores temperaturas superficiais, seguida pela tinta convencional (T9) e azul claro (T11), com absortâncias totais de $78,04 \%, 72,98 \%$ e $61,03 \%$ respectivamente.

Para as tintas de cor cinza escuro, ocorreram diferenças de aproximadamente $3^{\circ} \mathrm{C}$ entre suas temperaturas superficiais durante $\mathrm{o}$ período de medição. A amostra T13 (refletiva), apesar de apresentar tonalidade (aparência) mais escura, sua absortância média na região do infravermelho foi menor que da amostra T12 (cinza escuro convencional), o que resultou em menores temperaturas superficiais (Figura 13), comprovando a importância de se considerar a absortância em toda a faixa do espectro solar, e não apenas em relação à sua aparência (absortância no visível). Para as tintas de cor preta (amostras T14 e T15), as temperaturas superficiais da tinta refletiva foram inferiores à tinta preta convencional em média $5^{\circ} \mathrm{C}$, visto que a absortância solar da refletiva é menor, apesar de ambas apresentarem absortâncias no visível bastante baixas (Fig. 14 e Tabela 3). A diferença considerável na região do infravermelho faz com que a tinta refletiva preta apresente absortância total significativamente inferior à tinta preta convencional, comprovando-se assim a eficiência do desenvolvimento de tintas frias (refletivas) para diminuição das temperaturas superficiais de edificações, sem a necessidade de se usar apenas tonalidades claras nos edifícios.

A partir dos valores de absortância solar das tintas obtidos a partir de medições de refletância em espectrofotômetro e com base em medições de temperaturas superficiais de amostras pintadas com as tintas avaliadas, observa-se a relação direta entre estes dois parâmetros, principalmente quando se avalia tintas frias de cores correspondentes às tintas convencionais.

Figura 13: Temperaturas superficiais das tintas de cor cinza escuro.

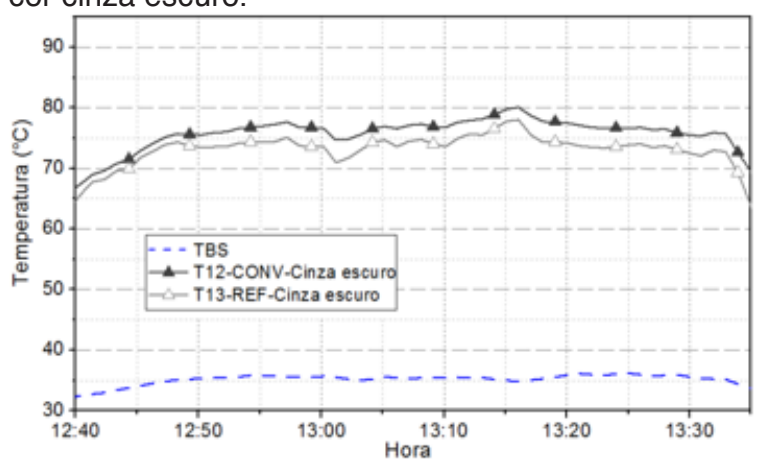

Figura 14: Temperaturas superficiais das tintas de cor preta.

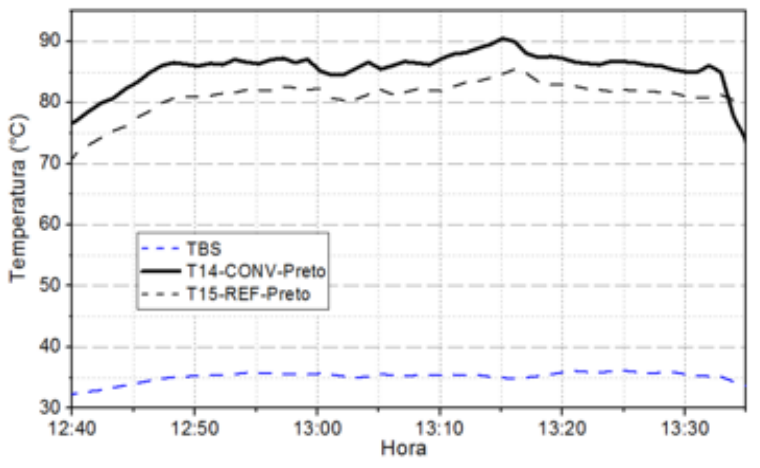

\section{Conclusões}

A comparação das curvas de absortância espectral das tintas e suas respectivas absortâncias médias por faixa do espectro permitem avaliar o desempenho térmico desses materiais de forma mais precisa, pois esses dados demonstram a diferença no comportamento espectral dos materiais quando expostos à radiação solar. 
As medições de emissividade confirmam a classificação das tintas como de alta emissividade, o que as caracterizam como bons emissores de radiação de onda longa, facilitando as perdas de calor das superfícies.

Pôde-se observar também, que tintas frias com baixa absorção no infravermelho-próximo, porém de cor e tonalidade iguais às tintas convencionais, resultam em tintas com menores absortâncias solares quando comparadas às convencionais. Este comportamento confirma a importância de se obter dados medidos em laboratório para caracterização térmica desses materiais, e não apenas pela percepção visual.

Além disso, as temperaturas superficiais das amostras expostas ao sol evidenciaram que a absortância solar das tintas afeta diretamente o desempenho térmico das superfícies pintadas, comprovando que quanto mais baixa é a absortância solar da tinta, menor a temperatura das superfícies do edifício, como indicam os resultados desta pesquisa. E que a absortância solar é resultante do efeito conjugado de absorção em todo o espectro solar, com efeito significativo da região do infravermelho-próximo.

Observou-se que o grande potencial de uso das tintas frias no envelope construtivo é resultado da diminuição da absortância solar na região do infravermelho, com a possibilidade de se utilizar cores de tonalidade mais escura, porém com melhor desempenho térmico quando comparadas com tintas convencionais de mesma cor.

\section{Agradecimentos}

Ao CNPq e à FAPESP pelas bolsas de pós-doutorado, ao Laboratório Interdisciplinar de Eletroquímica e Cerâmica (LIEC) da UFSCar pelas medições espectrofotométricas, ao Laboratório de Energia Solar da Escola de Engenharia da UFRGS pelas medições de emissividade, ao Sr. Prokopis, da Abolin Co. pelo fornecimento das amostras de tintas refletivas importadas e aos Professores Maurício Roriz e Victor Roriz pelo auxílio nas medições de temperaturas superficiais

\section{Referências}

AKBARI, H.; POMERANTZ, M.; TAHA, H. Cool surfaces and shade trees to reduce energy use and improve air quality in urban areas. Solar Energy, v.70, p.295-310, 2001.

ASTM. C1371-04: Standard test method for determination of emittance of materials near room temperature using portable emissometers. Philadelphia, 2004.

E903-12: standard test method for solar absorptance, reflectance, and transmittance of materials using integrating spheres. Philadelphia, 2012.

G173-03: standard tables for reference solar spectral irradiances - direct normal and hemispherical on $37^{\circ}$ tilted surface. Philadelphia, 2003.

ASHRAE. 74-1988: method of measuring solar-optical properties of materials. Atlanta, 1988.

ABNT. NBR 15220-1: desempenho térmico de edificações - parte 1: definições, símbolos e unidades. Rio de Janeiro, 2005.

BERDHAL, P.; BRETZ, S. E. Preliminary survey of the solar reflectance of cool roofing materials. Energy and Buildings, v.25, p.149-158, 1997.

DORNELLES, K. A. Absortância solar de superfícies opacas: métodos de determinação e base de dados para tintas látex acrílica e PVA. 2008. 160p. Tese (Doutorado) - Faculdade de Engenharia Civil, Arquitetura e Urbanismo, Universidade Estadual de Campinas, Campinas, 2008.

DORNELLES, K. A.; RORIZ, M.; RORIZ, V., CARAM, R. M. Desempenho térmico de tintas brancas com microesferas cerâmicas para uso em coberturas de edifícios. In: ENCAC E VII ELACAC, 11., 2011, Búzios. Anais... Búzios: ANTAC, 2011.

DOULOS, L.; SANTAMOURIS, M. LIVADA, I. Passive cooling of outdoor urban spaces: the role of materials. Solar Energy, v.77, p.231-249, 2004.

GOMES, R. J. Condicionamentos climáticos da envolvente dos edifícios para habitação: ensaio de aplicação ao caso da região de Lisboa. Lisboa: Ministério das Obras Públicas - Laboratório Nacional de Engenharia Civil. Memórias do LNEC, v.2, 1962.

LEVINSON, R.; AKBARI, H. ; REILLY, J. C. Cooler tile-roofed buildings with near infrared-reflective nonwhite coatings. Building and Environment v. 42, n.7, p. 2591 a 2605, 2007a.

LEVINSON, R.; BERDAHL, P.; AKBARI, H.; MILLER, W.; JOEDICKE, I. ; REILLY, J. Methods of creating solar-reflective nonwhite surfaces and their application to residential roofing materials. Solar Energy Materials and Solar Cells, v. 91, n.4, 2007b.

SYNNEFA, A.; SANTAMOURIS, M.; APOSTOLAKIS, K. On the development, optical properties and thermal performance of cool colored coatings for the urban environment. Solar Energy, v.81, p.488-497, 2007.

SYNNEFA, A.; SANTAMOURIS, M.; LIVADA, I. A study of the thermal performance and of reflective coatings for the urban environment. Solar Energy, v.80, p.968-981, 2006.

UEMOTO, K. L.; SATO, N. M. N.; JOHN, V. M. (2010), Estimating thermal performance of cool colored paints. Energy and Buildings, v.42, p.17-22. 